\title{
Article \\ Simulations of Decentration and Tilt of a Supplementary Sulcus-Fixated Intraocular Lens in a Polypseudophakic Combination Using Ray-Tracing Software
}

\author{
Grzegorz Labuz *, Gerd U. Auffarth (D, Weijia Yan, Timur M. Yildirim (D) and Ramin Khoramnia \\ The David J Apple Center for Vision Research, Department of Ophthalmology, University Hospital Heidelberg, \\ INF 400, 69120 Heidelberg, Germany; Gerd.Auffarth@med.uni-heidelberg.de (G.U.A.); \\ Weijia.Yan@med.uni-heidelberg.de (W.Y.); Timur.Yildirim@med.uni-heidelberg.de (T.M.Y.); \\ Ramin.Khoramnia@med.uni-heidelberg.de (R.K.) \\ * Correspondence: Grzegorz.Labuz@med.uni-heidelberg.de
}

Citation: Łabuz, G.; Auffarth, G.U.; Yan, W.; Yildirim, T.M.; Khoramnia, R Simulations of Decentration and Tilt of a Supplementary Sulcus-Fixated Intraocular Lens in a

Polypseudophakic Combination

Using Ray-Tracing Software.

Photonics 2021, 8, 309. https:// doi.org/10.3390/photonics 8080309

Received: 29 June 2021

Accepted: 29 July 2021

Published: 2 August 2021

Publisher's Note: MDPI stays neutral with regard to jurisdictional claims in published maps and institutional affiliations.

Copyright: (C) 2021 by the authors Licensee MDPI, Basel, Switzerland. This article is an open access article distributed under the terms and conditions of the Creative Commons Attribution (CC BY) license (https:// creativecommons.org/licenses/by/ $4.0 /)$

\begin{abstract}
This study aimed to assess image quality after the tilt and decentration of supplementary intraocular lenses (IOLs) in a two-lens configuration. One was designed for sulcus fixation with a nominal power range of 1D-10D and was combined with a capsular fixation 20D IOL. The optical performance of a ray-tracing model was tested under IOL misalignment through the area under the modulation transfer function (MTFa) and wave aberrations. Tilting by $10^{\circ}$ resulted in a $4 \%$ reduction of the MTFa for a 10D IOL as compared to $9 \%$ for the 20D lens. The two models demonstrated good tolerance to a $1 \mathrm{~mm}$ decentration; as for the 10D sulcus-fixated lens, the MTFa loss was $2 \%$, and $4 \%$ for the capsular fixation lens. Coma and astigmatism increased three- and four-fold, respectively, after a $10^{\circ}$ tilt compared to the aberration level induced by the $1 \mathrm{~mm}$ decentration. Both analyses showed a trend towards a lower MTF impact and fewer optical errors with decreasing nominal power. In conclusion, when misaligned, low-power sulcus-fixated IOLs might retain their good optical quality. An extreme tilt of $10^{\circ}$ has a more detrimental effect on the IOL performance than a $1 \mathrm{~mm}$ decentration. The proper alignment of a high-power capsular fixation lens is important in achieving a desirable postoperative outcome.
\end{abstract}

Keywords: supplementary IOLs; lens tilt and decentration; MTF; HOAs; polypseudophakia

\section{Introduction}

Phacoemulsification with intraocular lens (IOL) implantation into a capsular bag is a routine procedure for cataract treatment. Although cataract surgery is usually performed in patients over 60 years of age, refractive lens exchange, which results in clear crystalline lens removal and IOL implantation, may be offered to younger patients who wish to be spectacle independent [1]. This shift from cataract to refractive surgery reinforces the need for a continuous improvement of crystalline lens implants. Similarly, an accurate lens position is considered essential in obtaining satisfactory vision [2-14]. IOL performance is optimal when the lens is placed in an on-axis position, but precise centration is difficult to achieve during surgery [2-14]. While the incidence of severe tilt and dislocation may compromise vision [15], clinical studies have indicated that if the extent of the IOL's tilt and decentration is low, visual impairment might not be measurable [2]. Most of those studies have, however, been performed on capsule fixation IOLs [2-4,9-11,13-15]. Still, little is known about the tolerance to the misalignment of sulcus-fixated supplementary IOLs, which are also offered in refractive surgery.

Despite significant advances in biometry techniques and IOL power calculation, postoperative refractive errors may still occur in pseudophakic eyes [16]. Gayton and Sanders first described a piggyback technique in 1993 [17], which was initially used to correct postoperative hyperopia in microphthalmia. In 1999, Gayton et al. applied the 
same approach to correct myopia in normal and post-penetrating keratoplasty eyes [18]. However, the implantation of two IOLs into the capsular bag resulted in postoperative complications such as interlenticular opacification [19]. The use of sulcus-fixated IOLs that have purposely been designed to be implanted into the ciliary sulcus rather than the capsular bag is accepted as safe and efficacious when they are used in polypseudophakia to supplement or correct an iatrogenic refractive error arising from the implantation of the primary, capsular fixation lens [6-8,12]. Recently, the sulcus-fixated IOLs' application range moved beyond refractive error correction to reversible multifocality (i.e., bifocality or trifocality) in pseudophakic eyes $[6,8,20]$. Clinical studies have reported the postoperative misalignment of sulcus-fixated IOLs $[6,7,12]$ whose appearance might be exacerbated by their proximity to the pupil, which is often considered a reference. An off-axis position, which may coincide with the poor visual performance of unknown etiology, may prompt an early decision to explant the IOL. However, the impact of IOL misalignment on the optical quality of sulcus-implanted IOLs has rarely been studied. Decision making or explanations could be improved by a better understanding of the effects of misalignment. Though our group has recently shown that a $5^{\circ}$ tilt and a $0.6 \mathrm{~mm}$ decentration of a trifocal sulcus-fixated IOL minimally impacts the image quality [8], we only assessed a zero-power model in that study, and we recognized the need for further research using a range of powers. Moreover, a close distance between sulcus-fixated and capsular-fixated IOLs poses a challenge in simulating the misalignment of only the former lens in bench-top measurements. This could be resolved by ray-tracing simulations in a numerical model.

The purpose of this study was to evaluate the effect of the tilt and decentration of a sulcus-fixated IOL in simulated polypseudophakia. We applied a ray-tracing model and computed the eye's higher-order aberrations (HOAs) as well as their impact on the modulation transfer function (MTF) to assess the potential effects of sulcus-fixated lens misalignment on patients' vision.

\section{Materials and Methods}

\subsection{Intraocular Lenses}

We performed the optical simulations of ten sulcus-fixated supplementary IOLs, Sulcoflex Aspheric, 653L, (Rayner Ltd., Worthing, UK) with the nominal power ranging from $1 \mathrm{D}$ to $10 \mathrm{D}$ (in $1 \mathrm{D}$ increments). The IOLs were designed based on propriety data provided by Rayner Ltd. under a non-disclosure agreement. Each sulcus-fixated lens had an optic size of $6.5 \mathrm{~mm}$ and featured a convex anterior and a concave posterior surface. The lens featured a round edge to decrease the likelihood of pigmentary dispersion and secondary glaucoma.

To mimic a polypseudophakic condition, we included a $20 \mathrm{D}$ capsular fixation lens, the RayOne Aspheric, RAO600C, (Rayner Ltd., Worthing, UK) with a complete optical design provided by the manufacturer. The capsular fixation lens differed from the sulcusfixated lens as it had a smaller optic (i.e., $6 \mathrm{~mm}$ ), was biconvex, and had a sharp optic edge. However, the material characteristics were identical for both models, which were made of hydrophilic acrylic material (26\% water content) with the refractive index and an Abbe number of 1.46 and 56, respectively. Both had an aspheric ('aberration-neutral') design to minimize each IOL's spherical aberration and ensure diffraction-limited performance for a parallel beam.

\subsection{Ray-Tracing Simulations}

A model eye was built in OpticStudio (Radiant Zemax LLC, Redmond, WA, USA) in accordance with the data published by Liou and Brennan [21]. According to this model, the front and back corneal surfaces have a $7.77 \mathrm{~mm}$ and $6.40 \mathrm{~mm}$ radius of curvature, with a -0.18 and -0.60 asphericity, respectively. The central corneal thickness was $0.50 \mathrm{~mm}$. The anterior chamber depth was $3.16 \mathrm{~mm}$, which was the distance between the back surface of the cornea and the pupil. The retina shape was modeled as an asphere with a $-8.10 \mathrm{~mm}$ radius of curvature and a conic constant of 0.96 . The refractive index and the Abbe number 
of the cornea were 1.376 and 55.48, respectively. Although the aqueous humor had a slightly higher dispersion (50.37) than the vitreous (51.30), both shared a refractive index of 1.336. Ocular media dispersion was derived from the Atchison and Smith study [22] The crystalline lens was replaced with the RAO600C capsular fixation IOL, and a sulcusfixated supplementary lens was placed anteriorly with a $0.5 \mathrm{~mm}$ separation between the two lenses [6]. The sulcus-fixated lens was located $1.59 \mathrm{~mm}$ behind the pupil. The optical simulations were performed in polychromatic light, with the spectrum weight corresponding with the CIE photopic luminosity function. To account for the power difference between the sulcus IOLs, the distance between the primary lens and the retina for each model was modified using a minimum root-mean-square (RMS) wavefront focus adjustment.

The IOLs were compared according to their image quality metrics, which were evaluated utilizing a Huygens modulation transfer function (MTF) at a $3 \mathrm{~mm}$ pupil. The MTF was calculated for sagittal and tangential planes, and then averaged. The IOLs' tolerance to decentration (up to $1 \mathrm{~mm}$, with a $0.25 \mathrm{~mm}$ step) in the X (horizontal) and Y (vertical) directions with respect to the optical axis as well as IOL tolerance to tilt along a horizontal axis (up to $10^{\circ}$, with a $2.5^{\circ}$ step) were both tested. The pupil was decentered by $0.5 \mathrm{~mm}$ off the axis, as proposed by Liou and Brennan [23]. The impact of tilt and decentration on the imaging performance of each supplementary IOL was assessed in a two-lens configuration with the capsular fixation lens. For comparison, the tolerance to misalignment of the RayOne Aspheric with a centrally aligned $10 \mathrm{D}$ sulcus-fixated lens was also simulated. The IOLs were evaluated using a macro that computed and saved the MTF for each condition. MTF results were later analyzed with a dedicated MATLAB program (MathWorks Inc., Natick, MA, USA). Image deterioration was assessed by comparing the area under the MTF function (MTFa) [24], which was calculated based on the following formula:

$$
\mathrm{MTFa}=\sum_{f=0}^{f=50 / d} \operatorname{MTF}(f d)
$$

The maximum frequency $(f)$ used to calculate the MTF area was $50 \mathrm{lp} / \mathrm{mm}$, and the frequency step was $d=1 \mathrm{lp} / \mathrm{mm}$. The Huygen's point-spread function (PSF) was calculated and compared. Furthermore, the change in monochromatic aberrations $(555 \mathrm{~nm})$ was quantified by Zernike coefficients expressed up to the 6th order. The RMS was calculated for all higher-order terms (above the 6th term-Noll's notation). However, primary and secondary coma aberrations were only reported due to the low level of other higher-order aberrations (HOAs). Astigmatism induced due to IOL misalignment was calculated from the 5th and the 6th terms after power-vector conversion [25].

\section{Results}

Figure 1 shows the decrease of the MTFa as a function of tilt (A) and decentration (B). Tilt appears not to have an important impact on the optical quality up to $5^{\circ}$ for all IOLs, except for the primary lens. Above this level, the $10 \mathrm{D}$ sulcus-fixated lens' MTFa decreased slightly, with a sharp decrease above $7.5^{\circ}$. However, the lower the nominal power of the sulcus-fixated supplementary IOL, the more robust the optical performance was against tilt. Nevertheless, the maximum reduction of the MTFa for the $10 \mathrm{D}$ sulcus-fixated lens was $4 \%$, as compared to $9 \%$ for the $20 \mathrm{D}$ lens.

A lens decentration of up to $1 \mathrm{~mm}$ had a less deleterious effect on the optical quality than a $10^{\circ}$ tilt. The primary lens demonstrated a gradual decrease of the MTFa with decentration. The sulcus-fixated models were hardly affected by their off-axis position, with a $2 \%$ maximum MTFa reduction for the $10 \mathrm{D}$ sample and virtually no effect for lowerpower lenses. For the capsular fixation lens, decentration by $1 \mathrm{~mm}$ caused a mere $4 \%$ loss of image quality. 

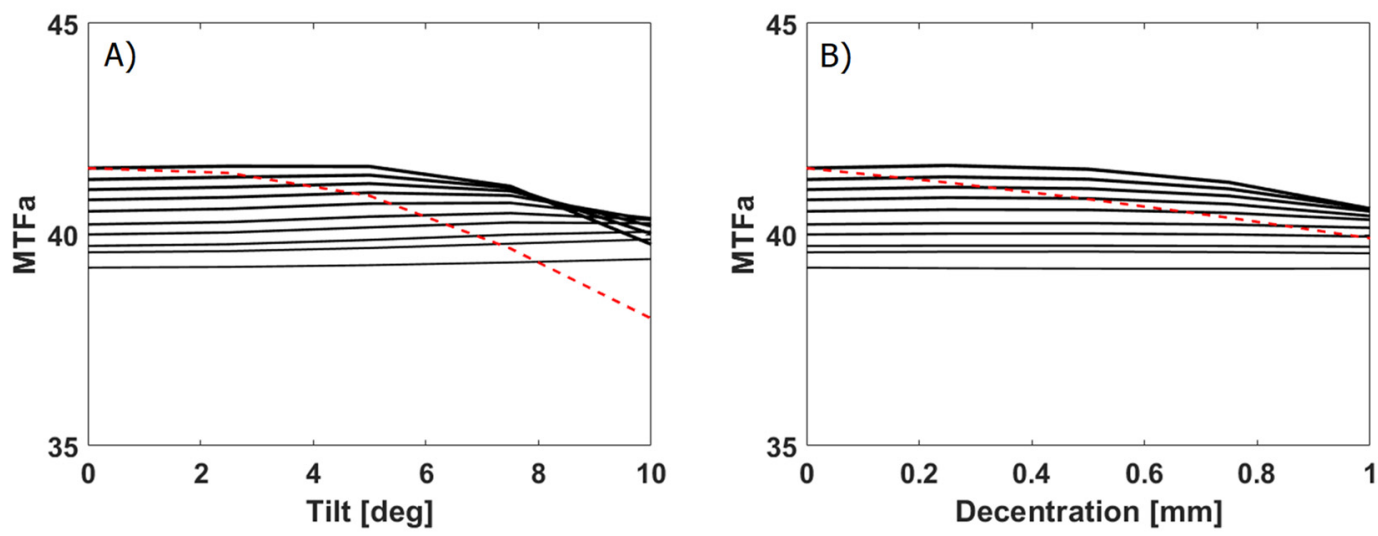

Figure 1. The impact of isolated tilt (A) and decentration (B). The solid black lines refer to 10 sulcus-fixated IOLs, with the nominal power from $1 \mathrm{D}$ (bottom line) to $10 \mathrm{D}$ (top line). The dashed red line indicates the $20 \mathrm{D}$ capsular fixation lens.

Figure 2 shows representative images of the combined impact of IOL misalignment on the MTF values. For the $3 \mathrm{D}$ lens, no changes in optical quality can be observed. For the $6 \mathrm{D}$, the effects of misalignment could only be noticed at the extreme ends of the surface plot. The MTFa of the 9 D IOL was only decreased at a higher tilt and $X=Y=1 \mathrm{~mm}$ decentration. The primary $(20 \mathrm{D})$ lens results confirmed that tilt impacts the optical quality more than decentration, with the largest separation between the five surfaces.
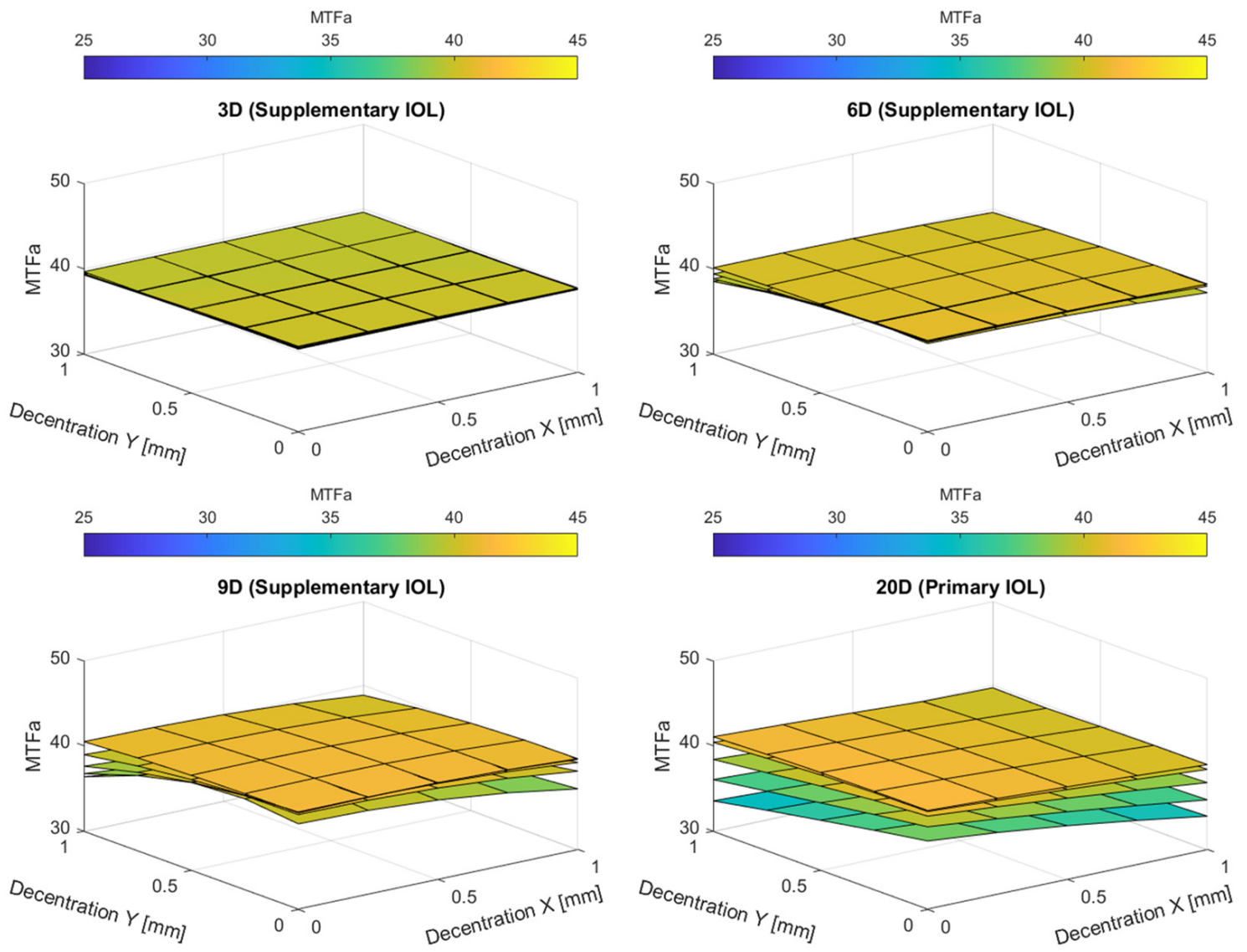

Figure 2. The effect of decentration and tilt on the optical quality of a $20 \mathrm{D}$ capsular fixation IOL, as well as 3,6 , and $9 \mathrm{D}$ sulcus-fixated IOLs in polypseudophakia. The imaging performance was quantified with the area under the modulation transfer function (MTFa). Each figure's top and bottom surfaces correspond to a condition with zero and $10^{\circ}$ tilt, respectively. For the $20 \mathrm{D}$ IOL, a $2.5^{\circ}$ tilt increase resulted in a gradual degradation of the optical quality, creating five distinct surfaces of the MTFa change. 
The PSF analysis presented in Table 1 confirms that the performance of the 3 D sulcusfixated IOL does not substantially differ under various severities of misalignments. For the $6 \mathrm{D} \mathrm{IOL}$, a slight change in the PSF appearance could be observed at a $10^{\circ}$ tilt, but for the other conditions, differences from the centered PSF were not apparent. Both the $9 \mathrm{D}$ and the $20 \mathrm{D}$ IOLs proved to be minimally affected by a $0.5 \mathrm{~mm}$ decentration, but at $1 \mathrm{~mm}$, an asymmetry of the PSF becomes visible, which is particularly pronounced at a $10^{\circ}$ tilt.

Table 1. The point-spread function of the IOLs assessed at the on-axis position, with decentration and tilt.

\begin{tabular}{|c|c|c|c|c|c|}
\hline \multirow[b]{2}{*}{ IOL } & \multirow[b]{2}{*}{ Centered } & \multicolumn{2}{|c|}{ Decentration } & \multicolumn{2}{|c|}{ Tilt } \\
\hline & & $0.5 \mathrm{~mm}$ & $1.0 \mathrm{~mm}$ & $5^{\circ}$ & $10^{\circ}$ \\
\hline $3 \mathrm{D}$ & ( ) & ( ) & - & 0 & 0 \\
\hline $6 \mathrm{D}$ & o & o) & o) & 0 & 0 \\
\hline $9 \mathrm{D}$ & o & (0) & (0) & o & 0 \\
\hline $20 \mathrm{D}$ & o & o) & (o) & 0 & \\
\hline
\end{tabular}

The coma aberrations' RMS and astigmatism are shown in Figure 3, confirming that the decrease of the optical quality with misalignment results from the combined effect of these two aberrations. An extreme tilt of $10^{\circ}$ yielded higher RMS and astigmatism levels than a $1 \mathrm{~mm}$ decentration. However, a gradual increase in these optical errors with the nominal power was observed in both types.
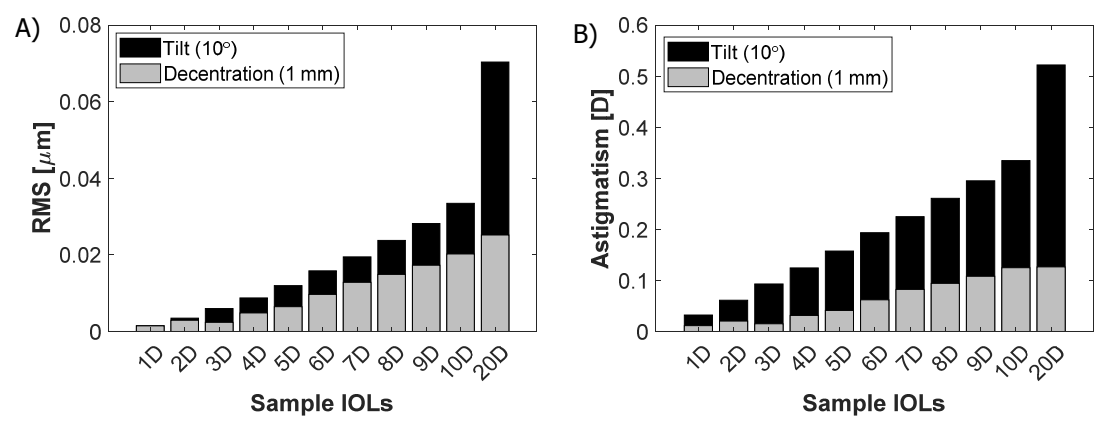

Figure 3. The root-mean-square (RMS) of the primary and secondary coma aberrations (A) and induced astigmatism $(\mathbf{B})$ in the studied IOLs under isolated $10^{\circ}$ tilt (black bars) and $1 \mathrm{~mm}$ decentration (gray bars) at a $3 \mathrm{~mm}$ aperture. 


\section{Discussion}

We demonstrated that the tilt and decentration of the sulcus-fixated supplementary IOLs in polypseudophakic configuration have minimal effect on the retinal image, expressed as MTFa. The capsular fixation lens appears to be less tolerant to tilt, but decentration alone did not substantially impact its imaging quality.

The sulcus-fixated supplementary IOLs showed robust performance against tilt and decentration. However, the gradual increase of the optical errors along with the IOL power indicates that susceptibility to misalignment depends on the IOL's refractive power. Another aspect is the asphericity level, as a higher nominal power yields a greater conic constant. These two factors may explain the smaller impact of IOL misalignment on the low-power supplementary IOLs in the sulcus as compared to the high-power capsular fixation lens.

Fujikado and Saika studied the misalignment effect in aspheric IOLs with various spherical aberration corrections (i.e., $-0.27 \mu \mathrm{m},-0.17 \mu \mathrm{m}$, and $-0.04 \mu \mathrm{m}$ ) [5]. They used a set of holders to simulate a $0.5 \mathrm{~mm}$ decentration and a $5^{\circ}$ tilt, and subsequently measured the ' HOAs of IOLs using a Hartmann-Shack device [5]. Although they detected increased coma aberration in all misaligned IOLs, the lens with the highest conic constant demonstrated a higher coma compared to the other designs [5]. The IOL with the lowest spherical aberration correction proved to have a higher tolerance to misalignment [5]. In the current study, the IOLs' optical performance did not substantially change despite a $1.0 \mathrm{~mm}$ decentration, which was also true for the capsular fixation lens. The good image quality retained by the high-power IOL might be due to its aberration-neutral design, which appears to be more robust against misalignment than that which corrects the positive spherical aberration of the cornea, as shown by Fujikado and Saika [5]. In subsequent studies, Tandogan et al. measured the impact of decentration up to $1.0 \mathrm{~mm}$ in another aberration-neutral lens using an optical-bench system. They found a slight change of the MTF at $50 \mathrm{lp} / \mathrm{mm}$ of 0.02 [14], which is in line with the results of the current study. Lee et al. demonstrated that the MTF of an extended depth-of-focus IOL with a $-0.27 \mu \mathrm{m}$ spherical-aberration correction deteriorates under $0.75 \mathrm{~mm}$ decentration more than its aberration-neutral counterpart [9]. Eppig et al. performed a ray-tracing analysis and showed that a $5^{\circ}$ tilt does not affect aberration-free IOLs [4], which was confirmed by our simulations. Although the performance of the capsular fixation lens presented only a $1 \%$ decrease of the MTFa under a $5^{\circ}$ tilt, an extreme tilt of $10^{\circ}$ may induce increased astigmatism and coma aberrations, thus potentially affecting patients' visual quality.

Fujikado and Saika also reported more coma aberration after tilting than after decentering the IOLs [5], which agrees with our findings, as we also obtained a higher RMS value following IOL tilt. In a clinical study by Taketani et al., 40 patients were implanted with spherical capsular fixation IOLs [13]. The level of IOL misalignment was quantified using a Scheimpflug topographer, and HOAs were assessed with a Hartmann-Shack aberrometer [13]. They identified the mean ( \pm standard deviation), a $3.43^{\circ}\left( \pm 1.55^{\circ}\right)$ tilt, and a $0.303( \pm 0.168) \mathrm{mm}$ decentration [13]. Taketani et al. reported a significant correlation of coma aberrations with tilt. However, no correlation was found between lens decentration and HOAs [13], which might have resulted from a smaller decentration range in their patients. In subsequent work, Oshika and co-workers applied a similar methodology to measure HOAs under the misalignment of sclera-sutured IOLs [10]. The level of tilt and decentration reported in that study was $4.43^{\circ}\left( \pm 3.02^{\circ}\right)$ and $0.279( \pm 0.162) \mathrm{mm}$, respectively. Thus, they confirmed Taketani's findings on the significant correlation of tilt with coma aberrations, with a minimal impact of decentration in their cohort $[10,13]$. Of the 45 eyes assessed by the Oshika group, only one had tilt beyond the range of the current study (i.e., $10^{\circ}$ ) [10]. In the Taketani et al. measurements, IOL tilt was found to be below $10^{\circ}$ in all patients, with a maximum of approximately $7^{\circ}$ and $0.7 \mathrm{~mm}$ of decentration [13]. A similar range of tilt in eyes implanted with either spherical or aspheric IOL was found by Baumeister et al. [2]. However, the mean value was lower, which was $2.85^{\circ}$ for spherical IOLs and $2.89^{\circ}$ for aspheric ones [2]. The mean decentration was $0.19( \pm 0.12) \mathrm{mm}$ for 
the former group and $0.27( \pm 0.16) \mathrm{mm}$ for the latter [2]. IOL misalignment observed by Baumeister et al. did not cause a significant reduction in the optical quality [2], indicating that moderate tilt and decentration have a low potential to affect the eye's visual function, which is in line with the conclusions of our current study.

The extent of IOL misalignment on the retinal image in pseudophakic eyes has been assessed in numerous studies [2-4,6,7,10-13]. Although in those publications, the average tilt typically did not exceed $4^{\circ}$ [4], Phillips et al. reported the mean value of $7.8^{\circ}$ [11] Taketani et al., Oshika et al., and Baumeister et al. $[2,10,13]$, discussed in detail in the preceding paragraph, provided evidence for improved tilt outcomes in modern cataract surgery, with mean values well below the level found by Phillips et al. Crnej et al. presented the results of their analysis of misalignment in eyes having plate-haptic IOLs, as well as one- and three-piece AcrySof lenses [3]. They used a Purkinje-image-based system to assess the lens position [3]. In the postoperative examination performed three months after the surgical procedure, tilt ranged from $-1.9^{\circ}\left( \pm 1.4^{\circ}\right)$ to $2.9^{\circ}\left( \pm 0.9^{\circ}\right)$ in the plate-haptic group, $2.6^{\circ}\left( \pm 4.1^{\circ}\right)$ to $5.3^{\circ}\left( \pm 2.4^{\circ}\right)$ in the three-piece group, and $1.9^{\circ}\left( \pm 0.3^{\circ}\right)$ to $2.2^{\circ}\left( \pm 7.2^{\circ}\right)$ in the one-piece group, with a significant variability indicated by a high SD in this group [3]. In that study, decentration was within a $0.07( \pm 0.28) \mathrm{mm}$ and $0.34( \pm 0.15) \mathrm{mm}$ range after plate-haptic IOL implantation, from $-0.08( \pm 0.57) \mathrm{mm}$ to $0.32( \pm 0.48) \mathrm{mm}$ with three-piece IOLs, and $0.08( \pm 0.30) \mathrm{mm}$ to $0.19( \pm 0.20) \mathrm{mm}$ with one-piece IOLs [3]. Decentration was generally within the $-1.0-1.0$ range, with only one case falling beyond this margin. The mean levels reported by Crnej et al. [3] were in agreement with the conclusions of Eppig et al. [4], who has also shown the populational variability of IOL decentration, with approximately $0.3 \mathrm{~mm}$ on average. The range observed in those publications helped select the lens displacement limits applied in this in vitro model to align our simulation with clinically relevant situations.

Given that the secondary implantation of a sulcus-fixated lens is performed less frequently than standard capsular fixation implantation, the available data on the misalignment of sulcus-fixated supplementary IOL are limited. One of the first reports on tilt and decentration in sulcus IOLs was presented by Kahraman and Amon [7]. Although they did not present the average level of misalignment in their series, they found $<0.5 \mathrm{~mm}$ decentration in one of their 12 cases, which did not compromise the visual function [7]. Prager et al. compared the decentration of capsular fixation and sulcus-fixated IOLs in a polypseudophakic configuration [12]. They found that the secondary (sulcus) IOLs yielded a smaller shift from the pupil center as compared to the primary (capsular fixation) IOLs $(0.22 \pm 0.02 \mathrm{~mm}$ vs. $0.29 \pm 0.03 \mathrm{~mm})$ in their population of 43 patients [12]. Gerten et al. recorded the largest off-axis deviation of $0.8 \mathrm{~mm}$ in one eye [6]. However, the decentration level was below the $0.5 \mathrm{~mm}$ threshold in $98.2 \%$ of their population [6]. The misalignment observed in that study did not affect the patients' vision despite the lens being bifocal [6]. The impact of the misalignment of a trifocal sulcus-fixated IOL has recently been studied by our group [8]. We found that decentration of up to $0.6 \mathrm{~mm}$ did not affect the far-focus performance of a zero-power trifocal lens in that laboratory investigation [8]. A slight reduction of the MTF was observed at the intermediate and near focus, and the negligible impact of a $5^{\circ}$ tilt [8]. That finding agrees with the current study's results on monofocal technology, as we also observed virtually no change in the MTFa of sulcus-fixated IOLs up to $5^{\circ}$.

Vega et al. studied the association of the MTFa with clinically measured visual acuity [24]. They set the MTFa reference level $=20$, above which the IOL's optical performance does not compromise visual acuity [24]. Given that the MTFa was above this level in all studied sulcus-fixated lenses, the expected impact of their misalignment on visual acuity is minimal. Although with a combined tilt and decentration, the bag-fixated lens demonstrated an MTFa $=31.6$, which is still above the reference level. The increase in coma and astigmatism aberrations may affect the patients' vision beyond the recognition of high-contrast letters. The presence of shadowing effects, reduced contrast sensitivity, or photic phenomena, typically associated with increased HOAs [26,27], might not be 
detected if only visual acuity is used in the postoperative assessment, as shown by our MTFa analysis.

Another limitation of our model is that it may not reflect the variability in the population. For instance, in this study, the off-the-center position of the pupil was marked by a $0.5 \mathrm{~mm}$ decentration. However, studies have shown that besides intersubject variability, pupil dilation may further influence the pupillary center's shift [28]. This variability in the natural centration of the pupil may influence how the misaligned IOL affects optical performance, as both a slight improvement or a deterioration, more substantial than observed in the current study, might be expected depending on the direction and the extent of each element's shift. In addition, we did not include corneal HOAs [29] or the dynamic behavior of the tear film [30]. However, further increasing the complexity of our model could introduce additional confounders, which would not necessarily improve the accuracy of our prediction as the complex interactions between each factor would then need to be studied in order to unmask the impact of IOL misalignment on optical quality. Including population data appears to be essential in the study of our results' repeatability, which warrants further research.

\section{Conclusions}

Ray-tracing simulations showed good imaging quality in a two-lens configuration. Decentration of up to $1 \mathrm{~mm}$ and tilt up to $7.5^{\circ}$ did not affect the optical performance of low-power sulcus-fixated IOLs in this simulated eye model. Although greater tilt (above $7.5^{\circ}$ ) resulted in a more substantial MTFa loss, its impact on visual performance might be limited. One would expect a similar effect in a pseudophakic eye. The precise alignment of a high-power capsular-bag-fixation lens appears to be essential in both standard single-lens implantation and the two-lens configuration.

Author Contributions: Conceptualization, G.E., G.U.A. and R.K.; methodology, G.Ł.; software, G.t.; validation, G.E., G.U.A. and R.K.; investigation, G.E., G.U.A., W.Y., T.M.Y. and R.K.; data analysis, G.E., W.Y. and T.M.Y.; resources, G.U.A. and R.K.; writing—original draft preparation, G.E., W.Y. and T.M.Y.; writing - review and editing, G.E., G.U.A. and R.K.; supervision, G.E., G.U.A. and R.K.; project administration, G.Ł., G.U.A. and R.K.; funding acquisition, G.U.A. and R.K. All authors have read and agreed to the published version of the manuscript.

Funding: This study was funded by unrestricted research grants from the Klaus Tschira Stiftung and Rayner Ltd. The sponsors had no role in the design, execution, interpretation, or writing of the study.

Institutional Review Board Statement: Not applicable.

Informed Consent Statement: Not applicable.

Data Availability Statement: The datasets used and analyzed for the present study are available from the corresponding author upon request.

Acknowledgments: Donald J. Munro contributed to the review of the manuscript.

Conflicts of Interest: G.U.A. reports grants, personal fees, non-financial support, and consulting fees from Johnson \& Johnson and Alcon; grants, personal fees, and non-financial support from Carl Zeiss Meditec, Hoya, Kowa, Oculentis/Teleon, Rayner, Santen, Sifi, and Ursapharm; grants and personal fees from Biotech, Oculus, and EyeYon; grants from Acufocus, Anew, Contamac, Glaukos, Physiol, and Rheacell, outside the submitted work. R.K. reports grants, personal fees, and non-financial support from Alcon, Johnson \& Johnson, Hoya, Physiol, and Rayner; personal fees and non-financial support from Kowa, Ophtec, Oculentis/Teleon, Santen, and Acufocus, outside the submitted work. G.E., W.Y., and T.M.Y. have nothing to disclose.

\section{References}

1. Hashemi, H.; Pakzad, R.; Yekta, A.A.; Aghamirsalim, M.; Pakbin, M.; Ramin, S.; Khabazkhoob, M. Global and regional prevalence of age-related cataract: A comprehensive systematic review and meta-analysis. Eye 2020, 34, 1357-1370. [CrossRef] [PubMed]

2. Baumeister, M.; Bühren, J.; Kohnen, T. Tilt and decentration of spherical and aspheric intraocular lenses: Effect on higher-order aberrations. J. Cataract. Refract. Surg. 2009, 35, 1006-1012. [CrossRef] 
3. Crnej, A.; Hirnschall, N.; Nishi, Y.; Gangwani, V.; Tabernero, J.; Artal, P.; Findl, O. Impact of intraocular lens haptic design and orientation on decentration and tilt. J. Cataract. Refract. Surg. 2011, 37, 1768-1774. [CrossRef]

4. Eppig, T.; Scholz, K.; Löffler, A.; Meßner, A.; Langenbucher, A. Effect of decentration and tilt on the image quality of aspheric intraocular lens designs in a model eye. J. Cataract. Refract. Surg. 2009, 35, 1091-1100. [CrossRef]

5. Fujikado, T.; Saika, M. Evaluation of actual retinal images produced by misaligned aspheric intraocular lenses in a model eye. Clin. Ophthalmol. 2014, 8, 2415-2423. [CrossRef]

6. Gerten, G.; Kermani, O.; Schmiedt, K.; Farvili, E.; Foerster, A.; Oberheide, U. Dual intraocular lens implantation: Monofocal lens in the bag and additional diffractive multifocal lens in the sulcus. J. Cataract. Refract. Surg. 2009, 35, 2136-2143. [CrossRef]

7. Kahraman, G.; Amon, M. New supplementary intraocular lens for refractive enhancement in pseudophakic patients. J. Cataract. Refract. Surg. 2010, 36, 1090-1094. [CrossRef]

8. $\quad$ Łabuz, G.; Auffarth, G.U.; Knorz, M.C.; Son, H.-S.; Yildirim, T.M.; Khoramnia, R. Trifocality Achieved Through Polypseudophakia: Optical Quality and Light Loss Compared with a Single Trifocal Intraocular Lens. J. Refract. Surg. 2020, 36, 570-577. [CrossRef]

9. Lee, Y.; Labuz, G.; Son, H.S.; Yildirim, T.M.; Khoramnia, R.; Auffarth, G.U. Laboratory assessment of the image quality of extended-depth-of-focus intraocular lens models in polychromatic light. J. Cataract. Refract. Surg. 2020, 46, 108-115. [CrossRef]

10. Oshika, T.; Sugita, G.; Miyata, K.; Tokunaga, T.; Samejima, T.; Okamoto, C.; Ishii, Y. Influence of tilt and decentration of scleral-sutured intraocular lens on ocular higher-order wavefront aberration. Br. J. Ophthalmol. 2007, 91, 185-188. [CrossRef]

11. Phillips, P.; Rosskothen, H.D.; Pérez-Emmanuelli, J.; Koester, C.J. Measurement of intraocular lens decentration and tilt in vivo. J. Cataract. Refract. Surg. 1988, 14, 129-135. [CrossRef]

12. Prager, F.; Amon, M.; Wiesinger, J.; Wetzel, B.; Kahraman, G. Capsular bag-fixated and ciliary sulcus-fixated intraocular lens centration after supplementary intraocular lens implantation in the same eye. J. Cataract. Refract. Surg. $2017,43,643-647$. [CrossRef]

13. Taketani, F.; Matuura, T.; Yukawa, E.; Hara, Y. Influence of intraocular lens tilt and decentration on wavefront aberrations. J. Cataract. Refract. Surg. 2004, 30, 2158-2162. [CrossRef]

14. Tandogan, T.; Son, H.S.; Choi, C.Y.; Knorz, M.C.; Auffarth, G.U.; Khoramnia, R. Laboratory Evaluation of the Influence of Decentration and Pupil Size on the Optical Performance of a Monofocal, Bifocal, and Trifocal Intraocular Lens. J. Refract. Surg. 2017, 33, 808-812. [CrossRef]

15. Oshika, T.; Kawana, K.; Hiraoka, T.; Kaji, Y.; Kiuchi, T. Ocular Higher-Order Wavefront Aberration Caused by Major Tilting Of Intraocular Lens. Am. J. Ophthalmol. 2005, 140, 744-746. [CrossRef]

16. Lundström, M.; Dickman, M.; Henry, Y.; Manning, S.; Rosen, P.; Tassignon, M.-J.; Young, D.; Stenevi, U. Risk factors for refractive error after cataract surgery: Analysis of 282811 cataract extractions reported to the European Registry of Quality Outcomes for cataract and refractive surgery. J. Cataract. Refract. Surg. 2018, 44, 447-452. [CrossRef]

17. Gayton, J.L.; Sanders, V.N. Implanting two posterior chamber intraocular lenses in a case of microphthalmos. J. Cataract. Refract. Surg. 1993, 19, 776-777. [CrossRef]

18. Gayton, J.L.; Sanders, V.; Van Der Karr, M.; Raanan, M.G. Piggybacking intraocular implants to correct pseudophakic refractive error. Ophthalmol. 1999, 106, 56-59. [CrossRef]

19. Werner, L.; Apple, D.J.; Pandey, S.K.; Solomon, K.D.; Snyder, M.E.; Brint, S.F.; Gayton, J.L.; Shugar, J.K.; Trivedi, R.; Izak, A.M. Analysis of elements of interlenticular opacification. Am. J. Ophthalmol. 2002, 133, 320-326. [CrossRef]

20. Khoramnia, R.; Yildirim, T.M.; Baur, I.; Auffarth, G.U. Duet procedure to achieve reversible trifocality. Ophthalmol. Z. Dtsch. Ophthalmol. Ges. 2020, 117, 999-1004.

21. ISO-11979-2. Part 2: Optical Properties and Test Methods, in Ophthalmic Implants—Intraocular Lenses; ISO: Geneva, Switzerland, 2014.

22. Atchison, D.A.; Smith, G. Chromatic dispersions of the ocular media of human eyes. J. Opt. Soc. Am. A 2005, 22, 29-37. [CrossRef]

23. Liou, H.-L.; Brennan, N.A. Anatomically accurate, finite model eye for optical modeling. J. Opt. Soc. Am. A 1997, 14, 1684-1695. [CrossRef] [PubMed]

24. Vega, F.; Millán, M.S.; Garzón, N.; Altemir, I.; Poyales, F.; Larrosa, J.M. Visual acuity of pseudophakic patients predicted from in-vitro measurements of intraocular lenses with different design. Biomed. Opt. Express 2018, 9, 4893-4906. [CrossRef]

25. Thibos, L.N.; Hong, X.; Bradley, A.; Cheng, X. Statistical variation of aberration structure and image quality in a normal population of healthy eyes. J. Opt. Soc. Am. A 2002, 19, 2329-2348. [CrossRef]

26. Sharma, M.; Wachler, B.S.B.; Chan, C.C.K. Higher Order Aberrations and Relative Risk of Symptoms After LASIK. J. Refract. Surg. 2007, 23, 252-256. [CrossRef]

27. Young, L.; Liversedge, S.P.; Love, G.D.; Myers, R.M.; Smithson, H.E. Not all aberrations are equal: Reading impairment depends on aberration type and magnitude. J. Vis. 2011, 11, 20. [CrossRef]

28. Wilson, M.A.; Campbell, M.C.W.; Simonet, P. The Julius F. Neumueller Award in Optics, 1989: Change of Pupil Centration with Change of Illumination and Pupil Size. Optom. Vis. Sci. 1992, 69, 129-136. [CrossRef]

29. Łabuz, G.; Varadi, D.; Khoramnia, R.; Auffarth, G.U. Progressive-toric IOL design reduces residual astigmatism with increasing pupil size: A ray-tracing simulation based on corneal topography data. Biomed. Opt. Express 2021, 12, 1568-1576. [CrossRef]

30. Napoli, P.E.; Nioi, M.; D'Aloja, E.; Fossarello, M. The Bull's Eye Pattern of the Tear Film in Humans during Visual Fixation on En-Face Optical Coherence Tomography. Sci. Rep. 2019, 9, 1-9. [CrossRef] 